\title{
Diabetes Mellitus: Beyond the Triopathy
}

Anubhav Chauhan*, Surat Singh, Yashwant Singh Parmar

Department of Ophthalmology, Govt. Medical College, Himachal Pradesh, India

*Corresponding author: Anubhav Chauhan, Department of Ophthalmology, Govt. Medical College, Himachal Pradesh, India, Tel: +919816991482; E-mail: chauhan.anubhav2@gmail.com

Received date: December 08, 2017; Accepted date: December 12, 2017; Published date: January 18, 2018

Copyright: $\odot 2018$ Chauhan A, et al. This is an open-access article distributed under the terms of the Creative Commons Attribution License, which permits unrestricted use, distribution, and reproduction in any medium, provided the original author and source are credited.

\begin{abstract}
When diabetes mellitus comes into question, the most common thing that strikes the mind of a physician is triopathy, cardiovascular status and secondary infections due to the immunosupressive state. Attention also needs to be paid to the examination of the oral cavity, auditory, complete ophthalmic, skin, pulmonary, gastrointestinal and muscular system in such patients, so that the work up of a diabetic patient becomes complete in all its aspects. A few noteworthy manifestations are discussed below.
\end{abstract}

Keywords: Diabetes; Manifestations; Workup

\section{Introduction}

An elevated blood glucose level is associated with dysfunction, damage and failure of various organs, especially the eyes, kidneys, nerves, heart and blood vessels [1]. The five classic complications associated with diabetes mellitus (DM) include retinopathy, neuropathy, and nephropathy, cardiovascular complications (coronary arterial disease, stroke and peripheral vascular disease) and delayed wound healing. Periodontal disease has recently been recognized as the "sixth complication" of DM. Oral involvement is in the form of periodontal disease, dental caries, fissured tongue, irritation fibroma, traumatic ulcers, lichen planus, recurrent aphthous stomatitis, xerostomia and burning mouth syndrome. Taste impairment has also been associated with the development of obesity and it has been reported during the course of diabetes [2].

Besides the diabetic retinopathy changes known to occur in DM, other significant ocular findings may be in the form of anterior ischemic optic neuropathy, diabetic papillopathy, cranial nerve palsy, ocular ischemic syndrome, retinal vein occlusion, retinal artery occlusion, glaucoma, dry eye and hence a complete ocular workup is mandatory [3]. Diabetic retinopathy changes in pregnancy need a special mention. In patients who had non proliferative diabetic retinopathy, studies demonstrated that as many as $50 \%$ of them may show an increase in their nonproliferative retinopathy during pregnancy. Approximately 5-20\% of these patients develop proliferative changes [4].

Skin involvement in DM is in the form of acanthosis nigricans, acrochordrons, diabetic dermopathy, rubeosis facei, stevens-johnson syndrome, necrobiosis lipoidica, vitiligo, bullosis diabeticorum, psoriasis, lichen planus, xerosis, sclerederma diabeticorum, granuloma annulare, onychodystrophy and periungual telangectasias to name a few [5]. Involvement of the auditory organ [6] and diabetic muscular infarction [7] has also been reported in DM. Despite the presence of a large capillary network in the lung, pulmonary complications of DM are frequently disregarded. This is mainly because the alveolarcapillary system is characterized by a great micro vascular reserve, and pulmonary abnormalities are commonly subclinical in diabetic patient. The rate of decline in respiratory function in diabetics has been found to be higher than in normal non-smoking subjects [8]. A restrictive lung disease pattern has also been reported [9].

In patients with diabetes, acute hyperglycaemia inhibits external anal sphincter function and decreases rectal compliance, potentially increasing the risk of fecal incontinence [10]. Glycogenic hepatopathy is characterized by elevated liver enzyme (especially transaminases), hepatomegaly, and glycogen accumulation within hepatocytes. There is no histological evidence that suggests that the enzyme elevations are due to liver necrosis, so the elevation is considered to be a result of hepatocyte's membrane injury leading to enzyme leakage instead of cell death [11]. The term "hepatogenous diabetes" is used to describe diabetes developing in patients with cirrhosis [12]. Diarrhea is a more common symptom in the diabetic population compared with controls. Besides diabetic enteropathy can itself cause diarrhea, drugs used to treat diabetes mellitus like metformin and acarbose can lead to diarrhea. Diabetic patients are more likely to have associated diseases (e.g., celiac sprue and microscopic colitis) and hence diarrhea in diabetes should not be taken lightly [13].

DM has been found to be associated with metabolic bone diseases, osteoporosis, fractures, as well as falls in geriatric patients. Indeed, DM not only aggravates osteopenia and osteoporosis, but is also one of the causes of both conditions. Bone loss is more in mothers with previously diagnosed DM or even with gestational DM [14].

\section{Conclusion}

The workup of a diabetic patient is exhaustive and time consuming; but should be carried out complete in all aspects. Knowledge of the lesser encountered features in DM should always be kept in mind so that the already "suffering" diabetic patient leads a life without suffering from complications of the disease.

\section{References}

1. American Diabetes Association (2010) Diagnosis and classification of diabetes mellitus. Diabetes Care 33: 62-69.

2. Leite RS, Marlow NM, Fernandes JK (2013) Oral Health and Type 2 Diabetes. Am J Med Sci 345: 271-273. 
Citation: Chauhan A, Singh S, Yashwant P (2018) Diabetes Mellitus: Beyond the Triopathy. J Diabetic Complications Med 3: 1000118. doi::

Page 2 of 2

3. Chauhan A, Sharma SD (2016) Comments on: Microvascular and macrovascular complications in diabetes mellitus: Distinct or continuum? Indian J Endocr Metab 20: 881-2.

4. Bhatia J, Sadiq MN, Chaudhary TA, Bhatia A (2007) Eye changes and risk of ocular medications during pregnancy and their management. Pak J Ophthalmol 23: 1-2.

5. Duff M, Demidova O, Blackburn S, Shubrook J (2015) Cutaneous Manifestations of Diabetes Mellitus. Clinical Diabetes 33: 40-8.

6. Dąbrowski M, Mielnik NG, Nowakowski A (2011) Involvement of the auditory organ in type 1 diabetes mellitus. Endokrynologia Polska 62: 138-144.

7. Shenavandeh S, Anushiravani A, Nazariniaet MA (2014) Diabetic muscle infarction and diabetic dermopathy two manifestations of uncontrolled prolong diabetes mellitus presenting with severe leg pain and leg skin lesions. J Diabetes \& Metabolic Disorders 13: 32-38.

8. Pitocco D, Fuso L, Conte EG, Zaccardi F, Condoluci C, et al. (2012) The Diabetic Lung - A New Target Organ? The Review of Diabetic Studies 9: 23-35.
9. Hamdy G, Amin M, Rashad A (2013) Pulmonary function changes in diabetic lung. Egyptian J Chest Diseases and Tuberculosis 62: 513-517.

10. Russo A, Botten R, Kong MF, Chapman IM, Fraser RJL, et al. (2004) Effects of acute hyperglycaemia on anorectal motor and sensory function in diabetes mellitus. Diabetic Medicine 21: 176-182.

11. Cha JH, Ra SH, Park YM, Ji YK, Lee JH, et al. (2013) Three cases of glycogenic hepatopathy mimicking acute and relapsing hepatitis in type I diabetes mellitus. Clinical and Molecular Hepatology 19: 421-425.

12. Krishnan B, Babu S, Walker J, Walker AB, Pappachan JM (2013) Gastrointestinal complications of diabetes mellitus. World J Diabetes 4: 51-63.

13. Gould M, Sellin JH (2009) Diabetic Diarrhea. Current Gastroenterology Reports11: 354-359.

14. Wongdee K, Charoenphandhu N (2011) Osteoporosis in diabetes mellitus: Possible cellular and molecular mechanisms. World J Diabetes 2: 41-48. 